\title{
NEUROLOGICAL COMPLICATIONS IN PATIENTS WITH TYPICAL HEMOLYTIC UREMIC SYNDROME
}

\author{
Mariana COSTIN ${ }^{1,2} \bowtie$, Anca BANULESCU ${ }^{1,2}$, loana ATANASESCU², Mihaela BALGRADEAN ${ }^{1,2}$ \\ 1 „Carol Davila“ University of Medicine and Pharmacy, Bucharest, Romania \\ 2 „M.S. Curie“ Children's Emergency Hospital, Bucharest, Romania
}

\author{
Received 08 Jan 2020, Accepted 11 Febr 2020 \\ hitps://doi.org/10.31688/ABMU.2020.55.1.25
}

\begin{abstract}
Introduction. Hemolytic uremic syndrome (HUS) is a hemorrhagic systemic microangiopathy, which primarily affects the kidney and is defined by the triad: acute renal failure, microangiopathic hemolytic anemia, and thrombocytopenia. We report two cases of HUS with neurological manifestations and different evolution.
\end{abstract}

Cases presentation. We report the cases of two young children, without significant medical history, who were diagnosed with acute renal failure, hemolytic anemia and thrombocytopenia. The onset of the disease was a few days prior to admission, with fever and diarrhea, for which they received symptomatic treatment at home, with worsening of the general condition. The particularity of these cases is that even if the patients had the featured triad of HUS and they were both diagnosed with this disease, the neurological complications evolved differently, with a finally favorable outcome.

Conclusions. Hemolytic uremic syndrome (HUS) is described as a multisystemic disease that affects mainly the kidney and is a major cause of morbidity and mortality in children less than 5 years old. The kidney and the brain are the main target organs in patients with HUS. In these two cases, the patients diagnosed with HUS and neurological complications, presented a favorable outcome with specific treatment.

\section{Résumé}

Complications neurologiques chez les patients atteints du syndrome hémolytique et urémique typique

Introduction. Le syndrome hémolytique et urémique (SHU) est une microangiopathie hémorragique systémique, qui affecte principalement le rein, définie par la triade: insuffisance rénale aiguë, anémie hémolytique micro-angiopathique et thrombocytopénie.

Nous rapportons deux cas de SHU avec des manifestations neurologiques et une évolution différente.

Description des cas. Nous rapportons les cas de deux jeunes enfants, sans antécédents médicaux importants, qui souffraient d'insuffisance rénale aiguë, d'anémie hémolytique et de thrombocytopénie. Lapparition de la maladie a eu lieu quelques jours avant l'admission, avec de la fièvre et de la diarrhée, pour lesquelles ils ont reçu un traitement symptomatique au domicile, avec l'aggravation de l'état général. La caractéristique de ces cas est que même si les patients présentaient la triade de SHU et étaient tous deux diagnostiqués avec cette maladie, les complications neurologiques avaient évolué différemment, avec un résultat favorable à la fin.

Conclusions. Le syndrome hémolytique et urémique (SHU) est décrit comme une maladie multi-systémique, qui affecte principalement le rein et c'est une cause 
Keywords: microangiopathy, thrombocytopenia, hemolytic uremic syndrome, neurological complications.

\section{INTRODUCTION}

Hemolytic uremic syndrome (HUS) is a hemorrhagic systemic microangiopathy, which primarily affects the kidney and is defined by the triad: acute renal failure, microangiopathic hemolytic anemia, and thrombocytopenia ${ }^{1}$. HUS often affects the central nervous system (CNS), neurological involvement representing a major cause of morbidity and mortality in children less than 5 years old ${ }^{2}$.

We report two cases of HUS with neurological manifestations and different evolution.

\section{Cases presentation}

In February 2016, a 1 year and 4 months old Caucasian boy was admitted at the Emergency Children's Hospital "Maria Skodlowska Curie". Nephrology Department, Bucharest, Romania, for fever $\left(39^{\circ} \mathrm{C}\right)$ and diarrheal stools with blood strips. The onset of the disease was 10 days prior to admission. He received symptomatic treatment at home, which resulted in worsening of the general condition.

On the day of presentation, physical examination revealed an ill-appearing child, with periods of unexplained irritability, heart rate of 110 beats/min, blood pressure of $120 / 70 \mathrm{mmHg}$, oxygen saturation (by pulse-oximetry) of $100 \%$. The skin was pale, with generalized petechial elements and decreased skin turgor, dark colored stools. The patient was oligoanuric in the last 12 hours. Heart and lung examinations were normal, abdomen was slim, without spontaneous pain or at touch, no hepatosplenomegaly. There were no signs of meningeal irritation.

Laboratory tests showed: leukocytosis (18.510/ $\mathrm{uL}$ ), hemolytic anemia ( $\mathrm{Hb} 10.4 \mathrm{~g} / \mathrm{dL}$ ), thrombocytopenia $(24.000 / \mathrm{uL})$, hepatic cytolysis syndrome (alanine aminotransferase $49 \mathrm{U} / \mathrm{L}$, aspartate aminotransferase 215 U/L). Peripheral blood smear showed schizocytes and fragmented erythrocytes. Rising nitrogen retention syndrome, with creatinine increasing from 1.29 to $6 \mathrm{mg} / \mathrm{dL}$ and blood urea nitrogen majeure de morbidité et de mortalité pour les enfants de moins de 5 ans. Le rein et le cerveau sont les principaux organes cibles dans le cas des patients atteints de SHU. Pour les deux cas présentés, les patients diagnostiqués avec SHU et avec des complications neurologiques, ont montré une évolution lentement favorable sous traitement spécifique.

Mots-clés: micro-angiopathie, thrombocytopénie, syndrome hémolytique et urémique, complications neurologiques.

increasing from 42 to $166 \mathrm{mg} / \mathrm{dL}$. Blood tests also showed positive for Verotoxin 1 and 2 .

Stool culture demonstrated the presence of enteropathogenic Escherichia Coli, producer of Shigatoxin, serotype O26.

Given the clinical manifestations of the patient and the laboratory findings, the diagnosis was that of typical hemolytic uremic syndrome. Supportive treatment was initiated and because of the rising nitrogen retention syndrome, we decided to start peritoneal dialysis.

Two days after admission, the patient began to experience periods of agitation, that alternated with periods of drowsiness ( $<1$ minute), followed by opisthotonus, myoclonus seizure, encephalitic screams. The patient was transferred to ICU (Intensive Care Unit). Peritoneal dialysis continued and pulse therapy was initiated with MetilPrednisolone $(30 \mathrm{mg} / \mathrm{kg} /$ dose), with a slowly evolving favorable outcome. For further evaluation, a cerebral computed tomography (CT) scan was done, which showed moderate brain edema. Other complications that occurred in evolution were : hypertension with moderate left ventricular hypertrophy, deep vein thrombosis on the common femoral vein.

The particularity of this case was that in the end, there was no neurological sequelae.

In the second case, a two-year-old girl was referred from a territorial hospital for hemolytic anemia, thrombocytopenia and acute renal failure. The onset of the disease was five days prior to admission, with fever $\left(38.5^{\circ} \mathrm{C}\right)$, diarrheal stools and vomiting.

The clinical examination revealed a general mediocre status, intense pallor, palpebral edema and lower limbs edema, petechial rash involving the face, upper and lower limbs, bilaterally audible vesicular breath sounds without rales, SpO2 99\%, rhythmic heart sounds, blood pressure of 116/80 $\mathrm{mmHg}$, heart rate of 100 beats/min, distended abdomen with diffuse pain, loose stools with mucus, no palpable hepatosplenomegaly. The patient was anuric in the last 12 hours. 
Laboratory results showed leukocytosis (19.360 $/ \mathrm{uL})$, hemolytic anemia $(\mathrm{Hb} 10.2 \mathrm{~g} / \mathrm{dL})$, thrombocytopenia (78.000/uL), hepatic cytolysis syndrome (alanine aminotransferase $166.3 \mathrm{U} / \mathrm{L}$, aspartate aminotransferase $106.5 \mathrm{U} / \mathrm{L}$ ), acute renal failure with creatinine rising from 4.6 to $7 \mathrm{mg} / \mathrm{dL}$ and blood urea nitrogen rising from 146.25 to $236 \mathrm{mg} / \mathrm{dL}$, lactate dehydrogenase $3071 \mathrm{U} / \mathrm{L}$. Negative stool cultures and negative verotoxin 1 and 2 assays.

The patient was diagnosed with hemolytic uremic syndrome and supportive treatment and peritoneal dialysis were initiated. Three days after admission in our clinic, the patient became sleepy, hyporesponsive and the respiratory rate decreased to $10-12$ breaths/minute, so the transfer to intensive care unit was decided. Cerebral computed tomography scan showed no signs of neurological damage at that time.

During the evolution, 7 days after admission, the patient presented eye deviation to the left, horizontal nystagmus and reduced response to verbal stimuli. The blood pressure raised to $184 / 119 \mathrm{mmHg}$ and suddenly the patient manifested seizures for short periods (20 seconds), with paradoxical movements of the mouth and myoclonic seizures.

Second cerebral CT scan described ischemic injuries in the right occipital region and the pulse therapy with MetilPrednisolone ( $30 \mathrm{mg} / \mathrm{kg} /$ dose) was initiated, with favorable evolution and slowly relief of symptoms.

Magnetic resonance imaging (MRI) showed bilateral occipital ischemic lesions associated with hypertensive encephalopathy. In terms of neurological sequelae, the patient presented external left hemianopia.

\section{Discussion}

Typical hemolytic uremic syndrome is most frequently triggered by Shigatoxin-producing Escherichia coli and manifests with prodromal diarrhea ${ }^{3}$.

SHU starts suddenly in infants and young children previously perfectly healthy and the multisystemic involvement increases the severity of the disease $^{4,5}$

The clinical features of these two patients were characterized by the same onset of the disease, with acute renal failure, microangiopathic hemolytic anemia, thrombocytopenia and even though both patients required peritoneal dialysis, in terms of neurological damage, things have evolved differently.

The first patient had no neurological sequelae, while the second one remained with external left hemianopia, with severe modifications on MRI.

\section{Conclusions}

Hemolytic uremic syndrome (HUS) is described as a multisystemic disease ${ }^{6,7}$ that affects mainly the kidney and is a major cause of morbidity and mortality in children under the age of 5 years old ${ }^{1}$. The kidney and brain are the main target organs affected in patients with HUS ${ }^{2}$.

In our two patients, they were diagnosed with HUS and neurological complications and their evolution was favorable under specific treatment. Patients had also severe acute renal damage (highest value of the creatinine $6-7 \mathrm{mg} / \mathrm{dL}$ and BUN $166-236 \mathrm{mg} / \mathrm{dL}$ ) and required a dialysis procedure.

Almost $50 \%$ of patients diagnosed with HUS require renal replacement therapy. Regarding differential diagnosis for HUS, we should consider conditions that present with concomitant findings of anemia, thrombocytopenia, and acute kidney injury. These include disseminated intravascular coagulation, thrombotic thrombocytopenic purpura, and inborn errors of vitamin $\mathrm{B} 12^{2}$.

\section{Author Contributions:}

M.C., A.B., and I.A. were responsible for the diagnostic procedures, clinical diagnosis, and treatment decisions. M.C. and M.B. wrote the manuscript. All authors have read and agreed to the published version of the manuscript.

\section{Compliance with Ethics Requirements:}

"The authors declare no conflict of interest regarding this article"

"The authors declare that all the procedures and experiments of this study respect the ethical standards in the Helsinki Declaration of 1975, as revised in 2008(5), as well as the national law. Informed consent was obtained from all the patients included in the study"

„No funding for this study“

\section{Acknowledgments: none}

\section{References}

1. Balgradean M, Croitoru A, Leibovitz E. An outbreak of hemolytic uremic syndrome in southern Romania during 2015-2016: epidemiologic, clinical, laboratory, microbiologic, therapeutic and outcome characteristics. Pediatrics and Neonatology. 2019;60:87-94.

2. Peron E, Zaharia A, Zota LC, et al. Early findings in outbreak of hemolytic uremic syndrome among young children caused by Shiga toxin-producing Escherichia coli. Romania, January to February 2016. Available at www.eurosurveillance.org. (accessed 04 Jan 2020). 
3. Ardissino G, Salardi S, Colombo E, et al. Epidemiology of hemolytic uremic syndrome in children. Data from the North Italian HUS network. Eur J Pediatr. 2016; 175:465.

4. Grisaru S. Management of hemolytic-uremic syndrome in children. International Journal of Nephrology and Renovascular Disease. 2014; 7:231-239.

5. Nathanson S, Kwon T, Elmaleh M, et al. Acute neurological involvement in diarrhea-associated hemolytic uremic syndrome. Clinical Journal of the American Society of Nephrology. 2010; 5(7):1218-1228.

6. Garg AX, Suri RS, Barrowman N, et al. Long-term renal prognosis of diarrhea-associated hemolytic uremic syndrome. A systematic review, meta-analysis, and meta regression. JAMA. 2003; 290(10):1360-1370.

7. Ghosh J, Gupta D, Chattopadhyay N. Hemolytic uremic syndrome. J Nephrol Ther. 2016; 6(2):1000239. 
